\title{
polymers
}

ISSN 2073-4360

www.mdpi.com/journal/polymers

Article

\section{Spectroscopic Investigation of Composite Polymeric and Monocrystalline Systems with Ionic Conductivity}

\author{
Darya V. Radziuk * and Helmuth Möhwald \\ Max-Planck Institute of Colloids and Interfaces, Am Mühlenberg 1, D14424 Potsdam, Germany; \\ E-Mail: helmuth.moehwald@mpikg.mpg.de \\ * Author to whom correspondence should be addressed; E-Mail: darya.radziuk@mpikg.mpg.de; \\ Tel.: +49-0-331-567-9447; Fax: +49-0-331-567-9202.
}

Received: 10 January 2011; in revised form: 1 March 2011 / Accepted: 23 March 2011 /

Published: 24 March 2011

\begin{abstract}
The conductivity mechanism is studied in the $\mathrm{LiCF}_{3} \mathrm{SO}_{3}$-doped polyethylene oxide by monitoring the vibrations of sulfate groups and mobility of $\mathrm{Li}^{+}$ion along the polymeric chain at different $\mathrm{EO} / \mathrm{Li}$ molar ratios in the temperature range from 16 to $90{ }^{\circ} \mathrm{C}$. At the high $\mathrm{EO} / \mathrm{Li}$ ratio (i.e., 30), the intensity of bands increases and a triplet appears at $1,045 \mathrm{~cm}^{-1}$, indicating the presence of free anions, ionic pairs and aggregates. The existence of free ions in the polymeric electrolyte is also proven by the red shift of bands in Raman spectra and a band shift to the low frequency Infra-red region at $65<\mathrm{T}<355{ }^{\circ} \mathrm{C}$. Based on quantum mechanical modeling, (method MNDO/d), the energies (minimum and maximum) correspond to the most probable and stable positions of $\mathrm{Li}^{+}$along the polymeric chain. At room temperature, $\mathrm{Li}^{+}$ion overcomes the intermediate state (minimum energy) through non-operating transitions (maximum energy) due to permanent intrapolymeric rotations (rotation of $\mathrm{C}, \mathrm{H}$ and $\mathrm{O}$ atoms around each other). In solid electrolyte $\left(\mathrm{Li}_{2} \mathrm{SO}_{4}\right)$ the mobility of $\mathrm{Li}^{+}$ions increases in the temperature range from 20 to $227{ }^{\circ} \mathrm{C}$, yielding higher conductivity. The results of the present work can be practically applied to a wide range of compact electronic devices, which are based on polymeric or solid electrolytes.
\end{abstract}

Keywords: polymer; electrolyte; lithium ion; battery; conductivity 


\section{Introduction}

The physics and chemistry of solid electrolytes requires expanding investigations in a new way due to the fabrication of devices of which they are the basis. Solid electrolytes (superionic conductors or solids with rapid ionic conductivity) are solids, which exhibit ionic conductivity comparable with that of electrolyte solutions or melted salts. Solids with rapid ionic conductivity have various applications from direct fuel cells [1], the improved ecological value of auto cars [2], and electrochemical capacitors [3]. The challenge in the application of solid electrolytes is in the bridging of the material structure with its physical properties, as well as the determination of ionic conductivity mechanisms; and their control over temperature and pressure. Ionic conductors can be divided into several classes according to the mechanism of conductivity.

- Common ionic crystals or semiconductors (e.g., $\mathrm{NaCl}, \mathrm{AgCl}$, etc.) with conductivity $<10^{-3} \mathrm{~S} \cdot \mathrm{cm}^{-1}$ due to thermal Frenkel-Schottky defects or impurity ions with minor quantities.

- Solid electrolytes or ionic superconductors (e.g., $\alpha-\mathrm{AgI}, \alpha-\mathrm{Li}_{2} \mathrm{SO}_{4}$, metal containing complexes of phosphates and silica phosphate, sour sulfates of base metals, etc.) with conductivity $<10^{-2} \mathrm{~S} \cdot \mathrm{cm}^{-1}$ due to the different structural disorder of one of the ionic sublattices.

- Polymeric electrolytes with conductivity in the $10^{-3}$ to $10^{-1} \mathrm{~S} \cdot \mathrm{cm}^{-1}$ region due to the transport of impurity cations along the polymeric chains with structural disorders [4].

As the first class of solid electrolytes is well studied [5-10], the electrical and optical properties of solid electrolytes of the second class are being intensively investigated. Among them are high temperature phases of $\alpha-\mathrm{Li}_{2} \mathrm{SO}_{4}\left(586-860{ }^{\circ} \mathrm{C}\right), \alpha-\mathrm{Ag}_{2} \mathrm{SO}_{4}\left(412-660{ }^{\circ} \mathrm{C}\right)$ sulfates of one-valent metals $\left(\mathrm{Li}^{+}, \mathrm{Na}^{+}\right.$and $\left.\mathrm{Ag}^{+}\right)$and also solids $\mathrm{Li}_{2} \mathrm{SO}_{4}-\mathrm{Na}_{2} \mathrm{SO}_{4}$ and $\mathrm{Li}_{2} \mathrm{SO}_{4}-\mathrm{Ag}_{2} \mathrm{SO}_{4}, \mathrm{Na}_{2} \mathrm{SO}_{4}$. Lithium $\alpha$-orthosilicate has an ionic conductivity of $3 \mathrm{~S} \cdot \mathrm{cm}^{-1}$ and is temperature sensitive, when doped with the metal oxides (e.g., titanium, zinc, magnesium or aluminum). The third class of polymeric electrolytes, which are polymers with lithium salt (e.g., $\mathrm{LiCF}_{3} \mathrm{SO}_{3}$ ), is least studied. Their conductivity is controlled by the change of the polymeric matrix, impurity salt and temperature [11-16].

Polyethylene oxide (PEO) as a simple polyether can be chosen as the polymeric matrix due to its low molecular weight and an ease of solubility in water. The solubility of the polymer in water is decreased with the increase of molecular weight, firmness and melting temperature. This fragment of structural formula of PEO is shown in Figure SI.1 (supporting information). Pristine PEO is a good dielectric in comparison to the other materials (Figure 1), but exhibits conductive properties when it is co-doped with sodium or lithium salts [17].

Figure 1. The diagram illustrating conductivity $\sigma\left(\mathrm{S} \cdot \mathrm{cm}^{-1}\right)$, which compares polyethylene oxide with other materials.

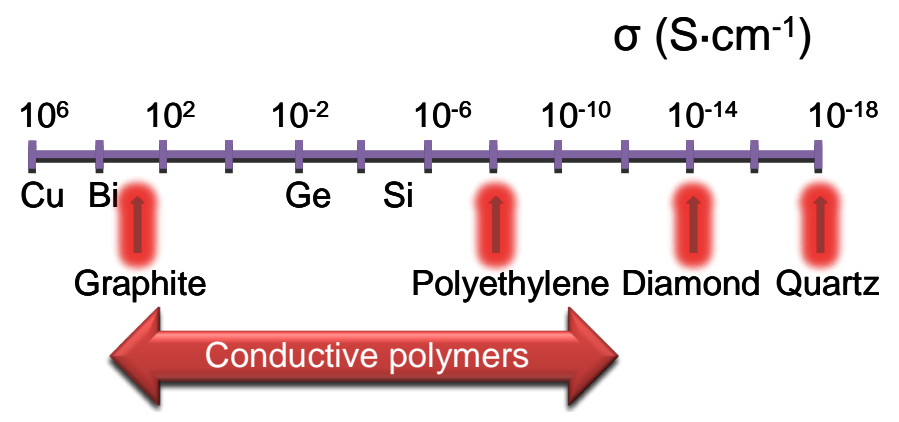


The physico-chemical properties of lithium and sodium salts are actively studied with the large interest in phase transitions of $\mathrm{LiASO}_{4}$ with $\mathrm{A}$ as the base cation (e.g., $\mathrm{Li}, \mathrm{Na}, \mathrm{K}, \mathrm{Rb}$ and $\mathrm{Cs}$ ) [18-20]. Small cationic compounds such as $\mathrm{Li}_{2} \mathrm{SO}_{4}$ and $\mathrm{LiNaSO}_{4}$ undergo superionic phase transitions at high temperatures. These structures have a cubic symmetry beyond the phase transitions and are characterized by complicated rotational disorders of sulfate anions, which is typical for plastic metals. The phase transitions of these structures were studied due to the orientation of one of the sulfate groups in the wide temperature range [21]. The high temperature phase of $\mathrm{Li}_{2} \mathrm{SO}_{4}$ is described as a plastic phase (i.e., a phase characterized by extensive orientation disorder of $\mathrm{SO}_{4}{ }^{2-}$ ions). In addition, monocrystal $\mathrm{Li}_{2} \mathrm{SO}_{4}$ exhibits rapid ionic conductivity. The low temperature phase $(\mathrm{T}=190 \mathrm{~K})$ of the crystal corresponds to the freezing process of orientation disorder of vibrations of sulfate ions, yielding a decrease in the electroconductivity of the substance [22].

The investigation of high temperature phases of the $\mathrm{Li}_{2} \mathrm{SO}_{4}$ structure is very interesting due to the fact that $\mathrm{Li}_{2} \mathrm{SO}_{4}$ is a monohydrate crystal with a monoclinic system at room temperature. The crystal belongs to the space group with symmetry $C_{2}{ }^{2}$ and is centric and cubic at $\mathrm{T}<848 \mathrm{~K}$ and at melting temperature $\mathrm{T}_{\text {melt }}=1,133 \mathrm{~K}$. As the chain length of $\mathrm{Li}-\mathrm{O}$ can vary from 1.09 to $1.9 \AA \mathrm{Li}_{2} \mathrm{SO}_{4}$ can be used for an accurate determination of the size and configuration of the sulfate group. A small radius of lithium ions allows for a close approach to the hydrogen atoms in order to examine the deformations of the sulfate group [23].

The main factor which limits the ionic conductivity of such a conductor is the nature of coupling and aggregation of ions in polymeric electrolytes [24-28]. Completely amorphous polymeric electrolyte systems with conductivity at room temperature were invented as an alternative to solid polyelectrolytes. Solutions of lithium salts in polymers such as polyphosphate with ethylene oxide groups or polymers from ethylene oxide and methylene oxide are amorphous conductors. The conductivity of these materials is controlled by the temperature, the nature of polymers and the concentration of lithium ions. The disadvantage of such compounds relates to the instability of sizes. However the electrolytes, which are formed from the polyethylene oxide, exhibit mechanical stability at high ionic conductivity and temperature, which is far below melting point $[29,30]$.

The main purpose of our work is to study ionic species (e.g., $\mathrm{SO}_{4}{ }^{2-}$ and $\mathrm{Li}^{+}$) in two conductive systems - polymeric and solid electrolytes. The vibrations of sulfate groups are examined by Raman and Infra-red spectroscopy in the temperature region from 65 to $355{ }^{\circ} \mathrm{C}$. At room temperature the presence of free ions or ionic aggregates is studied at different molar ratios of ethylene oxide to $\mathrm{LiCF}_{3} \mathrm{SO}_{3}$ salt $(\mathrm{EO} / \mathrm{Li})$ in the polymeric electrolyte with 2,3 and 11 chain lengths of dimethyl ethylene glycol ((EG) $\left.{ }_{n} \mathrm{DME}\right)$. The mobility of the $\mathrm{Li}^{+}$cation is modeled by a modified quantum mechanical method of molecular and atomic orbitals in the polyelectrolyte and spectroscopically studied solid electrolytes in the temperature region from 293 to $500 \mathrm{~K}$.

\section{Results and Discussion}

\subsection{Spectroscopy of Polymeric Electrolytes Based on $\mathrm{LiCF}_{3} \mathrm{SO}_{3}$ and Polyethylene Oxide}

Raman spectroscopy is employed to examine vibrations of ions in polymeric electrolytes because triflate anions $\mathrm{CF}_{3} \mathrm{SO}_{3}{ }^{-}$are very sensitive to coordination state. Three bands at $1,033,1,043$ 
and $1,053 \mathrm{~cm}^{-1}$ are assigned to free anions, ionic couples and ionic aggregates, respectively. Free ions dominate in solutions of $\mathrm{LiCF}_{3} \mathrm{SO}_{3}$ in $\mathrm{H}-\left[\mathrm{OCH}_{2} \mathrm{CH}_{2}\right]_{\mathrm{n}}-\mathrm{OH}(\mathrm{n}=1-4)$, while the number of ionic couples is small due to the presence of ionic associates [28].

The Raman spectrum of pristine $\mathrm{LiCF}_{3} \mathrm{SO}_{3}$ at room temperature is shown in Figure SI.5 (supporting information) and the peaks of corresponding vibrations are listed in the Table 1. From the spectra of pure $\mathrm{LiCF}_{3} \mathrm{SO}_{3}$ (Figure SI.5) the symmetric vibration of anion $\mathrm{SO}_{3}^{-}$at $1,034 \mathrm{~cm}^{-1}$ is the most interesting. Nonperturbed $\mathrm{CF}_{3} \mathrm{SO}_{3}{ }^{-}$ion has pyramidal symmetry $\left(C_{3 v}\right)$ with the sum of the normal vibrational modes $3 A_{1}+A_{2}+6 E$. Seven vibrations, which are observed for $\mathrm{LiCF}_{3} \mathrm{SO}_{3}$ solutions in (EG) ${ }_{11}$ DME in Raman spectra are shown in Figure 2. The vibration of $\mathrm{SO}_{3}{ }^{-}$is very sensitive to the medium due to the characteristic band of free $\mathrm{CF}_{3} \mathrm{SO}_{3}{ }^{-}$near $1,032 \mathrm{~cm}^{-1}$ in a strongly diluted $\mathrm{LiCF}_{3} \mathrm{SO}_{3}$.

Table 1. Vibrations of pure $\mathrm{LiCF}_{3} \mathrm{SO}_{3}$ at room temperature.

\begin{tabular}{c|c}
\hline $\begin{array}{c}\text { Wavenumber } \\
\left(\mathbf{c m}^{\mathbf{- 1}}\right)\end{array}$ & $\begin{array}{c}\text { Labeling of } \\
\text { frequencies }\end{array}$ \\
\hline $314_{\mathrm{s}}$ & $A_{1}\left({ }_{\nu} C-S\right)$ \\
\hline $349_{\mathrm{s}}$ & $\left.E{ }_{\nu} S O_{3}\right)$ \\
\hline $524_{\mathrm{w}}$ & $E\left({ }_{\delta} C F_{3}\right)$ \\
\hline $575_{\mathrm{m}}$ & $A_{1}\left({ }_{\delta} S O_{3}\right)$ \\
\hline $758_{\mathrm{s}}$ & $A_{1}\left({ }_{\delta} C F_{3}\right)$ \\
\hline $1034_{\mathrm{vs}}$ & $A_{1}\left({ }_{\nu} S O_{3}\right)$ \\
\hline $1230_{\mathrm{sh}}$ & $A_{1}\left({ }_{\nu} C F_{3}\right)$ \\
\hline
\end{tabular}

Figure 2. Raman spectra of $\mathrm{LiCF}_{3} \mathrm{SO}_{3}+(\mathrm{EG})_{11} \mathrm{DME}(\mathrm{EO} / \mathrm{Li}=10)$ at room temperature. $(\mathrm{EG})_{11} \mathrm{DME}$ is dimethyl ethylene glycol with the chain length $\mathrm{n}=11$ and $\mathrm{EO} / \mathrm{Li}=10$ is the inverse molar ratio of $\mathrm{LiCF}_{3} \mathrm{SO}_{3}$ to elements of ethylene oxide oligomer. Where 'vs', 's' and ' $\mathrm{m}$ ' are spectral bands with 'very strong', 'strong' and 'medium' intensity, respectively. The assignments 'sh' indicates a band shoulder, ' $w$ ' - a bandwidth, ' $\delta$ ' and ' $v$ '- the deformations and valency vibrations in the corresponding molecular groups, respectively.

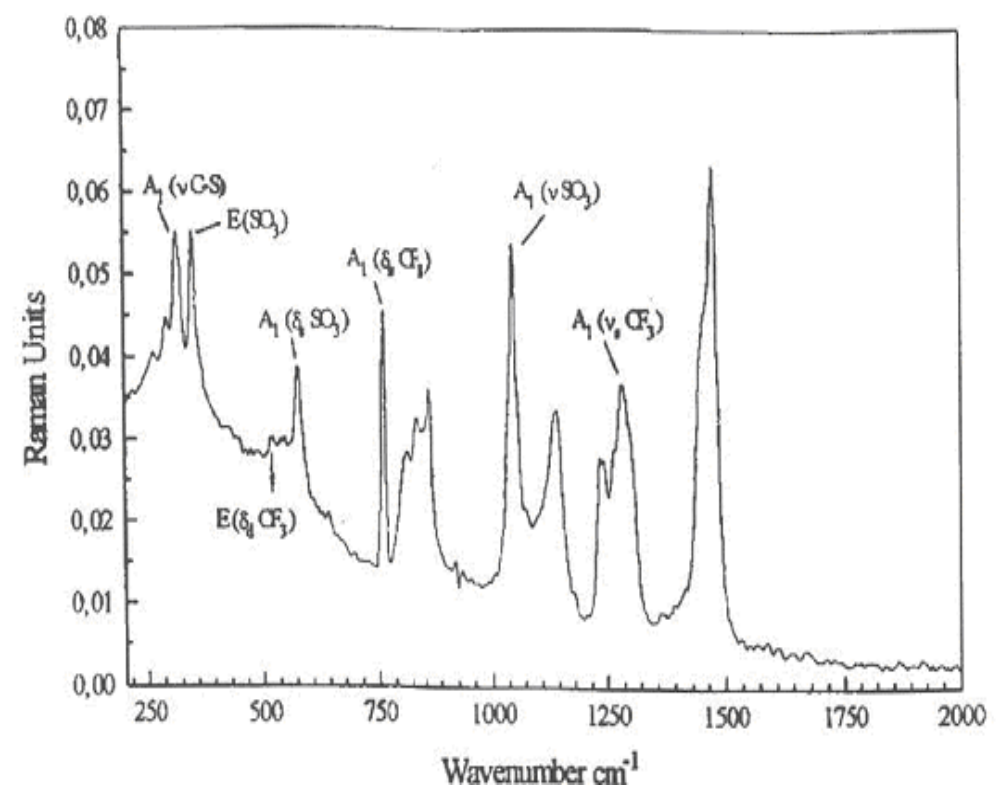


Raman bands of $\mathrm{SO}_{3}{ }^{-}$in $\mathrm{LiCF}_{3} \mathrm{SO}_{3}+(\mathrm{EG})_{\mathrm{n}} \mathrm{DME}$ with $\mathrm{n}=2$ and 11 in the range from $289 \mathrm{~K}$ to $363 \mathrm{~K}$ are shown in Figure 3. Both bands are broad with a distinct peak near $1,047 \mathrm{~cm}^{-1}$ and shoulders at $1,034 \mathrm{~cm}^{-1}$ with both chain lengths $\left(\mathrm{n}=2\right.$ and 11). Raman band of $\mathrm{SO}_{3}{ }^{-}$in $\mathrm{LiCF}_{3} \mathrm{SO}_{3}+$ $(\mathrm{EG})_{2} \mathrm{DME}$ acquire a shoulder near $1,053 \mathrm{~cm}^{-1}$ at the highest temperature $363 \mathrm{~K}$ (Figure $3(\mathrm{~A})$ ) and near $1,058 \mathrm{~cm}^{-1}$ with $\mathrm{n}=11$ (Figure 3(B)).

Figure 3. Raman spectra of dimethyl ethylene glycol with the chain lengths 2 (A) and 11 (B) $(\mathrm{EG})_{2} \mathrm{DME}$ and $(\mathrm{EG})_{11} \mathrm{DME}$ and $\mathrm{EO} / \mathrm{Li}=10$ inverse molar ratio of $\mathrm{LiCF}_{3} \mathrm{SO}_{3}$ to elements of ethylene oxide oligomer in a temperature range of $289 \mathrm{~K}$ to $363 \mathrm{~K}$.

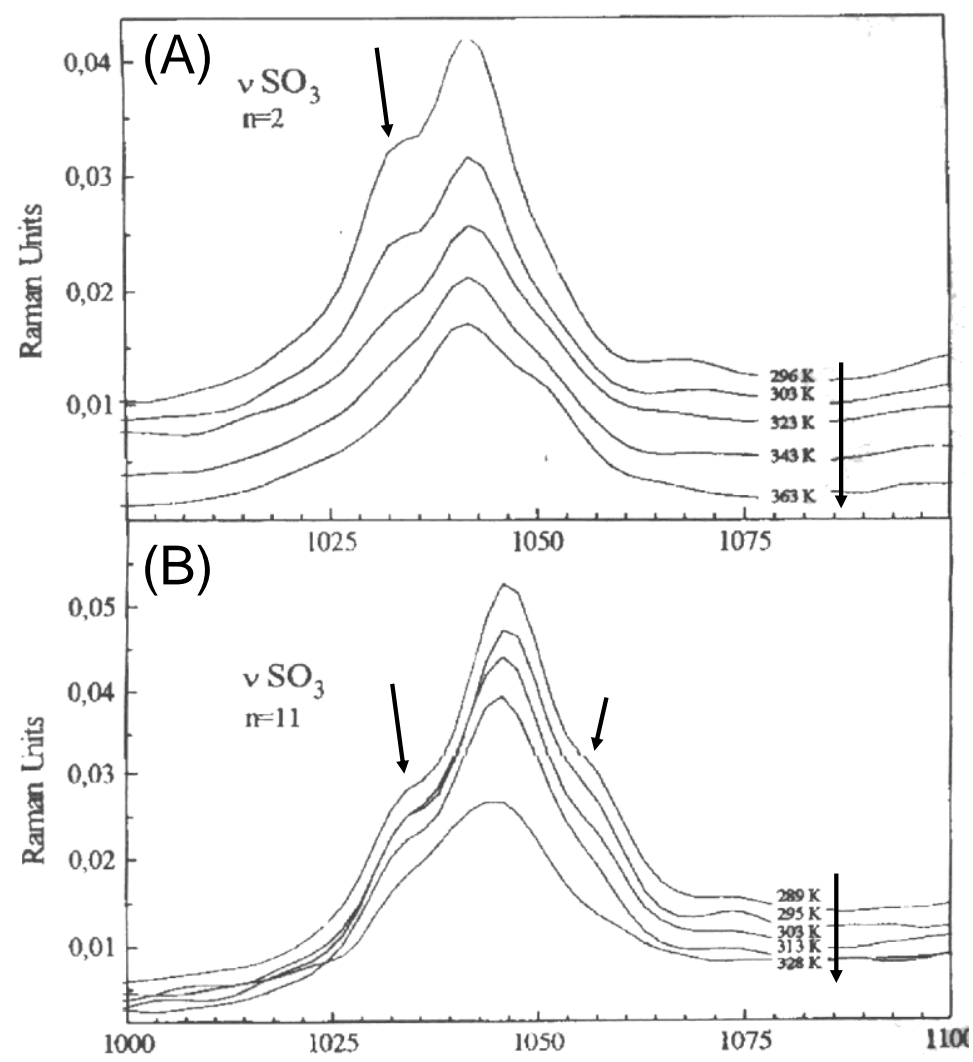

The bands become broader with lower intensity due to the temperature increase, indicating formation of ionic aggregates. Raman spectra of $\mathrm{LiCF}_{3} \mathrm{SO}_{3}+(\mathrm{EG})_{\mathrm{n}} \mathrm{DME}(\mathrm{n}=2$ and 11) at a concentration of EO/Li from 10 to 30 at room temperature show a relatively broad band with two maxima in the range of $1,025 \mathrm{~cm}^{-1}$ to $1,050 \mathrm{~cm}^{-1}$ (Figure 4). Both bands with $\mathrm{LiCF}_{3} \mathrm{SO}_{3}+(\mathrm{EG})_{\mathrm{n}} \mathrm{DME}$ ( $\mathrm{n}=2$ and 11) exhibit maximum shoulders near $1,037 \mathrm{~cm}^{-1}$ and near $1,043 \mathrm{~cm}^{-1}$ (Figure 4(A) and 4(B)). The intensity of $\mathrm{LiCF}_{3} \mathrm{SO}_{3}+(\mathrm{EG})_{2} \mathrm{DME}$ band at $1,045 \mathrm{~cm}^{-1}$ increases with the receding of $\mathrm{EO} / \mathrm{Li}$ from 30 to 10 (Figure 4(A)), while the band of $\mathrm{LiCF}_{3} \mathrm{SO}_{3}+(\mathrm{EG})_{11} \mathrm{DME}$ at $1,043 \mathrm{~cm}^{-1}$ is shifted to $1,047 \mathrm{~cm}^{-1}$ at $\mathrm{EO} / \mathrm{Li}=15$ and to $1,047 \mathrm{~cm}^{-1}$ at $\mathrm{EO} / \mathrm{Li}=10$ (Figure $4(\mathrm{~B})$ ), indicating changes in the number of free ions, ionic pairs and aggregates. 
Figure 4. Raman spectra of dimethyl ethylene glycol with chain lengths 2 (A) and 11 (B) $\mathrm{LiCF}_{3} \mathrm{SO}_{3}+(\mathrm{EG})_{n} \mathrm{DME}$ at a concentration of $\mathrm{EO} / \mathrm{Li}$ inverse molar ratio of $\mathrm{LiCF}_{3} \mathrm{SO}_{3}$ to elements of ethylene oxide oligomer from 10 to 30 at room temperature (A).

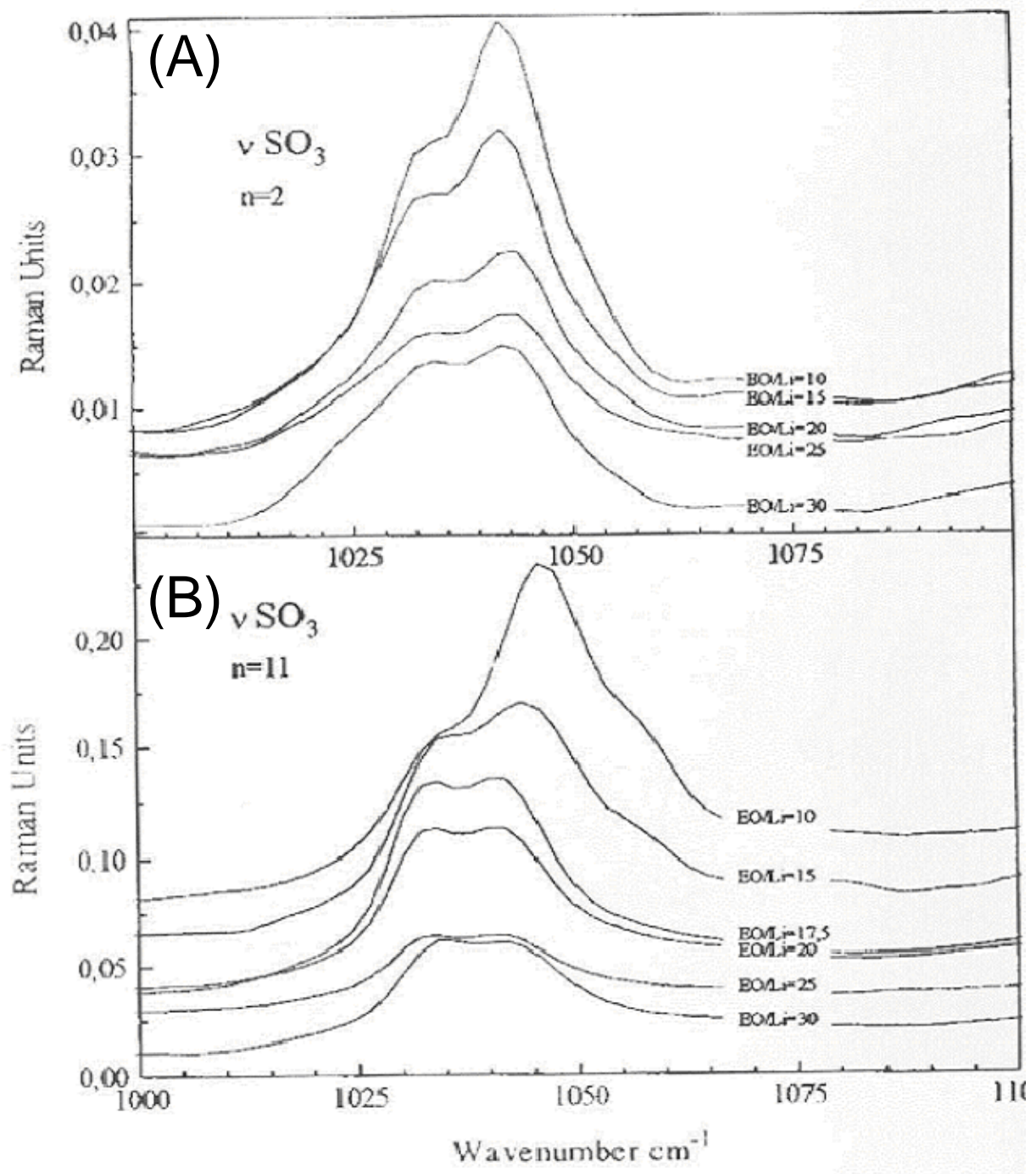

In $\mathrm{LiCF}_{3} \mathrm{SO}_{3}+(\mathrm{EG})_{11} \mathrm{DME}$ at $\mathrm{EO} / \mathrm{Li}=10$ additional peaks appear at $1,045 \mathrm{~cm}^{-1}$ and $1,054 \mathrm{~cm}^{-1}$, which are assigned to ionic pairs and associates like $\left\{\mathrm{CF}_{3} \mathrm{SO}_{3}{ }^{-} \ldots \mathrm{Li}^{+}\right\},\left\{\mathrm{Li}^{+} \ldots \mathrm{CF}_{3} \mathrm{SO}_{3}{ }^{-} \ldots \mathrm{Li}^{+}\right\}$and $\left\{\mathrm{CF}_{3} \mathrm{SO}_{3}{ }^{-} \ldots \mathrm{Li}^{+} \ldots \mathrm{CF}_{3} \mathrm{SO}_{3}{ }^{-}\right\}$(Figure 5). Based on the literature, the triplet, which is observed at $1,045 \mathrm{~cm}^{-1}$ is attributed to free ions, ionic pairs and ionic aggregates at the higher frequency region [24]. Therefore, one can deduce that the concentration of free anions (i.e., $\mathrm{CF}_{3} \mathrm{SO}_{3}{ }^{-}$and $\mathrm{SO}_{3}{ }^{-}$) in $\mathrm{LiCF}_{3} \mathrm{SO}_{3}+(\mathrm{EG})_{11} \mathrm{DME}$ at $\mathrm{EO} / \mathrm{Li}=10$ and $\mathrm{EO} / \mathrm{Li}=30$ is increased [31]. The Raman frequencies of $(\mathrm{EG})_{\mathrm{n}} \mathrm{DME}$ ( $\mathrm{n}=2$ and 11$)$ with interpretations are listed in Table 2 (supporting information) and are in a good agreement with the literature $[22,23,32,33]$. 
Figure 5. Band decomposition of symmetric valence vibration of $\mathrm{SO}_{3}{ }^{-}$in $\mathrm{LiCF}_{3} \mathrm{SO}_{3}+(\mathrm{EG})_{11} \mathrm{DME}$ at $\mathrm{EO} / \mathrm{Li}=10$ at room temperature.

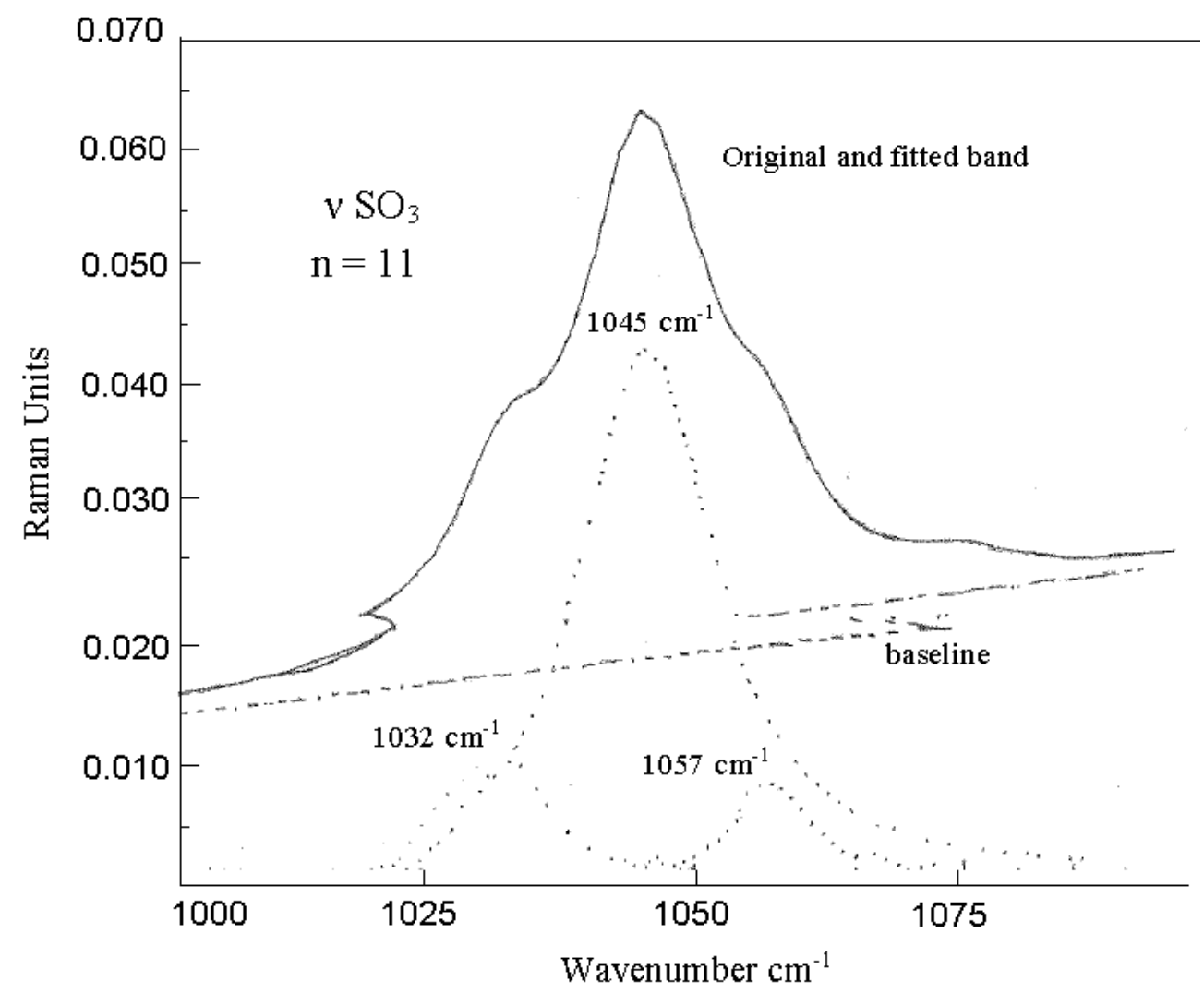

Free ions, ionic pairs and ionic aggregates can be studied in polyethylene oxide doped $\mathrm{LiCF}_{3} \mathrm{SO}_{3}$ by examination of the shape of Raman bands. For instance, spectral vibrations of anion $\mathrm{SO}_{3}{ }^{-}$become broader if the temperature is increased from 289 to $363 \mathrm{~K}$, indicating ionic aggregates. Later, the Raman spectral bands of either free or aggregated tetrahedral $\mathrm{SO}_{4}{ }^{2-}$ anions, surrounded by $\mathrm{Li}^{+}$or Na $^{+}$ cations, are studied at a higher temperature region of 328 to $573 \mathrm{~K}$.

\subsection{Spectral Features of Ionic Conductors, Which Are Based on $\mathrm{Na}_{2} \mathrm{SO}_{4}$ and $\mathrm{Li}_{2} \mathrm{SO}_{4}$}

Raman Spectra of $\mathrm{Li}_{2} \mathrm{SO}_{4}$ at Different Temperatures

Single lattice $\mathrm{Li}_{2} \mathrm{SO}_{4}$ contains 28 atoms, which correspond to the 84 degrees of freedom vibrations. All of the two or three-dimensional presentations split up the one-dimensional presentation $A$ due to the low side symmetry $\left(C_{1}\right)$. Group factor $C_{2 h}$ transforms any group presentation into $A_{g}+B_{g}+A_{u}+B_{u}$. The minimal structure presentation of the vibrational modes in $\mathrm{Li}_{2} \mathrm{SO}_{4}$ can be introduced as follows (Equations 1-4).

$$
\begin{gathered}
\Gamma\left(v_{1}\right)=A g+B g+A u+B u \\
\Gamma\left(v_{2}\right)=2 A g+2 B g+2 A u+2 B u \\
\Gamma\left(v_{3}\right)=\Gamma\left(v_{4}\right)=3 A g+3 B g+3 A u+3 B u \\
\Gamma_{S O_{4}}(\text { trans })=\Gamma_{S O_{4}}(\text { rot })=3 A g+3 B g+3 A u+3 B u
\end{gathered}
$$


Translational and rotational degrees of freedom become lattice modes in the crystal $\mathrm{Li}_{2} \mathrm{SO}_{4}$. For a $\mathrm{Li}^{+}$ion any translational degree of freedom corresponds to $A$, and the correlation group factor is considered as the minimal presentations of $\mathrm{Li}^{+}$ion movement (Equation 5).

$$
\Gamma_{L i}(\text { trans })=6 A g+6 B g+6 A u+6 B u
$$

The most intense peak $(A g)$ in Raman spectra is assigned to ${ }_{v 1} \mathrm{SO}_{3}{ }^{-}$at $1,014 \mathrm{~cm}^{-1}$ [34]. Less intense peaks $(A g)$ at $1,127,1,123$ and $1,194 \mathrm{~cm}^{-1}$ and three peaks $(B g)$ symmetry at $1,116,1,150$ and $1,204 \mathrm{~cm}^{-1}$ are attributed to the free ${ }_{v 3} \mathrm{SO}_{3}{ }^{-}$ion. The intramolecular movement $v_{4}$ generates two modes in $A g$ presentation at 617 and $666 \mathrm{~cm}^{-1}$ and three modes in $B g$ symmetry at 623,649 and $666 \mathrm{~cm}^{-1}$. Shoulder at $650 \mathrm{~cm}^{-1}$ is assigned to $A g$ geometry of scattering. It is difficult to find the differences between effects of shift and peak positions at $\sim 650$ and $\sim 666 \mathrm{~cm}^{-1}$ in both ( $\mathrm{Ag}$ and $B g$ ) presentations. The intramolecular mode $v_{2}$ of $E$ symmetry in the isolated ion split into two $\mathrm{Ag}$ and $\mathrm{Bg}$ modes in the crystal. There are two modes at 513 and $446 \mathrm{~cm}^{-1}$ in $A g$ presentation and those at 516 and $451 \mathrm{~cm}^{-1}$ in the $B g$ scattering symmetry. The intensities of $A g$ modes, which are observed in the XY geometry, are much weaker than those in YY [23]. The bandwidths corresponding to $A g$ and $B g$ at higher frequencies (i.e., 513 and $516 \mathrm{~cm}^{-1}$, respectively) of $v_{2}$ vibrations are broader than those which correspond to the other intramolecular modes in $\mathrm{Li}_{2} \mathrm{SO}_{4}$. In addition, the bands at 513 and $516 \mathrm{~cm}^{-1}$ are relatively high for $v_{2}$ components in comparison to other sulfate crystals. Normally $v_{2}$ components are in the region of 460 to $480 \mathrm{~cm}^{-1}$ in the $\mathrm{Li}_{2} \mathrm{SO}_{4} \cdot \mathrm{H}_{2} \mathrm{SO}_{4}, \mathrm{LiNaSO}_{4}$ and $\mathrm{LiKSO}_{4}$, where one of the $A g$ components is observed at $513 \mathrm{~cm}^{-1}$ and of $B g$ components is at $516 \mathrm{~cm}^{-1}$. Several translational modes of $\mathrm{Li}^{+}$ion can be connected due to their presence in the region of $400-450 \mathrm{~cm}^{-1}$ and the appearance of a group factor component $v_{2}$ with the corresponding symmetry.

Figure 6 shows the dependence of $v_{1}\left(469 \mathrm{~cm}^{-1}\right), v_{2}\left(646 \mathrm{~cm}^{-1}\right)$ and $v_{3}\left(1,123 \mathrm{~cm}^{-1}\right)$ vibrations of $\mathrm{Li}_{2} \mathrm{SO}_{4}$ on temperature in the range from 55 to $300{ }^{\circ} \mathrm{C}$. As the temperature increases, the vibration bands are shifted to the lower frequency range. The bandshifts of $v_{1}$ and for each $v_{2}$ and $v_{3}$ vibrations are 9 and $17 \mathrm{~cm}^{-1}$.

Figure 6. The dependence of $\mathrm{Li}_{2} \mathrm{SO}_{4} v_{1}\left(469 \mathrm{~cm}^{-1}\right), v_{2}\left(646 \mathrm{~cm}^{-1}\right)$ and $v_{3}\left(1,123 \mathrm{~cm}^{-1}\right)$ vibrations on temperature in the range from 55 to $300{ }^{\circ} \mathrm{C}$.

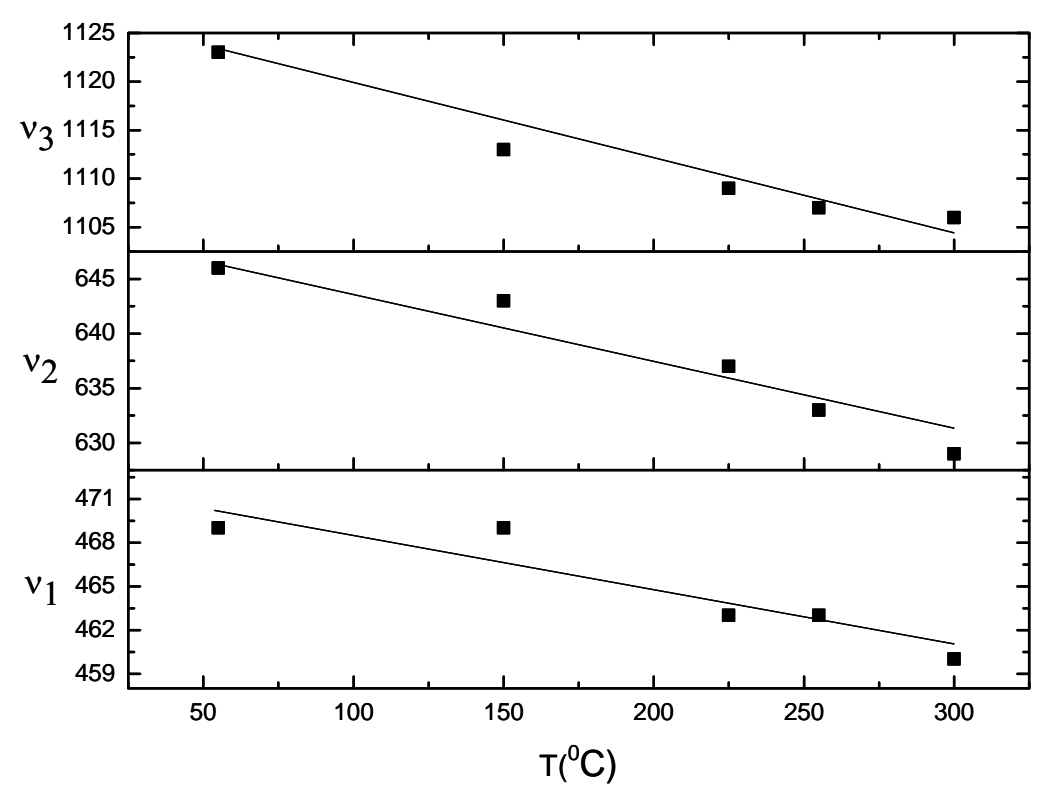




\subsection{Interpretation of Raman Spectra of $\mathrm{Na}_{2} \mathrm{SO}_{4}$}

Free tetrahedral $\mathrm{SO}_{4}{ }^{2-}$ ion has four types of fundamental vibrations ${ }_{v 1} \mathrm{SO}_{4},{ }_{22} \mathrm{SO}_{4},{ }_{v 3} \mathrm{SO}_{4},{ }_{v 4} \mathrm{SO}_{4}$ with corresponding wavenumbers (Table 3). The most intense bands of $\mathrm{SO}_{4}{ }^{2-}$ ion vibrations are the following: i) $994 \mathrm{~cm}^{-1}$ for the all components of ${ }_{v 1} \mathrm{SO}_{4}$ tensor; ii) 450 and $456 \mathrm{~cm}^{-1}$ for the $\mathrm{YY}$ and $\mathrm{ZZ}$ components of polarization ${ }_{v 2} \mathrm{SO}_{4}$ tensor, respectively; iii) $1,103,1,133$ and $1,156 \mathrm{~cm}^{-1}$ for the $\mathrm{XY}, \mathrm{YZ}$ and $\mathrm{ZX}$ components of polarization ${ }_{v 3} \mathrm{SO}_{4}$ tensor, respectively; iv) 633 and $651 \mathrm{~cm}^{-1}$ for the $\mathrm{ZX}$ and $\mathrm{YZ}$ components of polarization ${ }_{v 4} \mathrm{SO}_{4}$, respectively [35].

Table 3. Assignment of frequencies $\left(\mathrm{cm}^{-1}\right)$ in Raman spectra of $\mathrm{Na}_{2} \mathrm{SO}_{4}$ crystal.

\begin{tabular}{c|c|c|c|c|c|c}
\hline $\mathbf{X X}$ & $\mathbf{Y Y}$ & $\mathbf{Z Z}$ & $\mathbf{X Y}$ & $\mathbf{Y Z}$ & $\mathbf{Z X}$ & Vibrations \\
\hline- & $87 \mathrm{w}$ & $87 \mathrm{w}$ & $87 \mathrm{w}$ & $87 \mathrm{w}$ & - & $\mathrm{TAS}$ \\
$140 \mathrm{w}$ & $140 \mathrm{w}$ & $140 \mathrm{w}$ & $140 \mathrm{w}$ & $140 \mathrm{w}$ & $140 \mathrm{w}$ & - \\
$166 \mathrm{vw}$ & $166 \mathrm{vw}$ & $161 \mathrm{w}$ & $166 \mathrm{w}$ & - & $166 \mathrm{w}$ & $\mathrm{LA}$ \\
- & $\mathbf{4 5 0 s}$ & $\mathbf{4 5 6 v s}$ & - & $456 \mathrm{w}$ & $456 \mathrm{w}$ & ${ }_{22} \mathrm{SO}_{4}$ \\
$472 \mathrm{~m}$ & $472 \mathrm{w}$ & - & $469 \mathrm{w}$ & $469 \mathrm{w}$ & $469 \mathrm{w}$ & ${ }_{22} \mathrm{SO}_{4}$ \\
- & $622 \mathrm{w}$ & - & $625 \mathrm{w}$ & $625 \mathrm{w}$ & - & ${ }^{24} \mathrm{SO}_{4}$ \\
$639 \mathrm{w}$ & - & $639 \mathrm{~m}$ & - & - & $\mathbf{6 3 3 v s}$ & ${ }^{24} \mathrm{SO}_{4}$ \\
- & $650 \mathrm{w}$ & $650 \mathrm{w}$ & $651 \mathrm{w}$ & $\mathbf{6 5 1 s}$ & - & ${ }^{24} \mathrm{SO}_{4}$ \\
$\mathbf{9 9 4 v s}$ & $\mathbf{9 9 4 v s}$ & $\mathbf{9 9 4 v s}$ & $\mathbf{9 9 4 s}$ & $\mathbf{9 9 4 v s}$ & $\mathbf{9 9 4 v s}$ & ${ }^{21} \mathrm{SO}_{4}$ \\
- & $1106 \mathrm{w}$ & - & $\mathbf{1 1 0 3 v s}$ & $1103 \mathrm{w}$ & $1103 \mathrm{vw}$ & ${ }^{23} \mathrm{SO}_{4}$ \\
- & $1136 \mathrm{w}$ & $1136 \mathrm{w}$ & $1133 \mathrm{w}$ & $\mathbf{1 1 3 3 s}$ & $1133 \mathrm{vw}$ & ${ }^{2} \mathrm{SO}_{4}$ \\
$1156 \mathrm{w}$ & - & $1156 \mathrm{~m}$ & $1156 \mathrm{w}$ & $1156 \mathrm{w}$ & $\mathbf{1 1 5 6 v s}$ & ${ }_{\mathrm{v} 3} \mathrm{SO}_{4}$ \\
\hline
\end{tabular}

In the table, XX, YY, ZZ, XY, YZ, ZX indicate a symmetry of vibration, which is determined from the investigation of experimental tensors of Raman spectra. The characteristics of the bands intensity are illustrated in arbitrary units: ' $v w$ ' (very weak, $<10^{3}$ ), ' $w$ ' (weak, $1-2 \times 10^{3}$ ), ' $\mathrm{m}$ ' (medium, 4-8 $\times 10^{3}$ ), ' $s$ ' (strong, $8-10 \times 10^{3}$ ) and ' $v s^{\prime}$ ( very strong, $>10 \times 10^{3}$ ). The vibrations of the crystal lattice are given as ' $\mathrm{T}$ ' (translational) and ' $\mathrm{L}$ ' (libratory), while that of $\mathrm{SO}_{4}{ }^{2-}$ and $\mathrm{Na}$ atom are indicated by an ' $\mathrm{S}$ ' and an 'A', respectively. The vibrations of $\mathrm{SO}_{4}{ }^{2}$ are assigned by ${ }_{v 1} \mathrm{SO}_{4}$ as the most intense and fully symmetric nondegenerate, ${ }_{{ }_{2}} \mathrm{SO}_{4}$ and ${ }_{{ }_{3}} \mathrm{SO}_{4}$ are twice and thrice degenerate vibrations, while ${ }_{v 4} \mathrm{SO}_{4}$ is ascribed as a deformation vibration.

The symmetry of vibrations in the Table 3 is determined from experimental tensors of Raman spectra (Equation 6).

$$
\alpha_{v}=\left(\begin{array}{lll}
I_{x x} & I_{x y} & I_{x z} \\
I_{y x} & I_{y y} & I_{y z} \\
I_{z x} & I_{z y} & I_{z z}
\end{array}\right)
$$

where $I_{i j}$ is the scattering intensity with $i$ and $j$ as combinations of $\mathrm{x}, \mathrm{y}$ and $\mathrm{z}$ from experimental data and tensor components $\alpha_{v}$, which cannot be directly determined. The intensity $I_{i j}$ ( $i$ and $j$ indicate the directions of excited and scattered light) is measured for each vibration $v$. For example, $I_{x x}$ indicates the direction coincidence of the excited and scattered light $\vec{E}$. The investigation of components of Raman 
tensor requires an application of linearly polarized and excited light as well as an analysis of the polarization state of scattered light relative to crystallographic orientations of the sample under study [35].

The components of the tensor are relative intensities of Raman bands for different crystal orientations, positions of the analyser and polarizers (Table 4).

Table 4. Components of a polarization tensor.

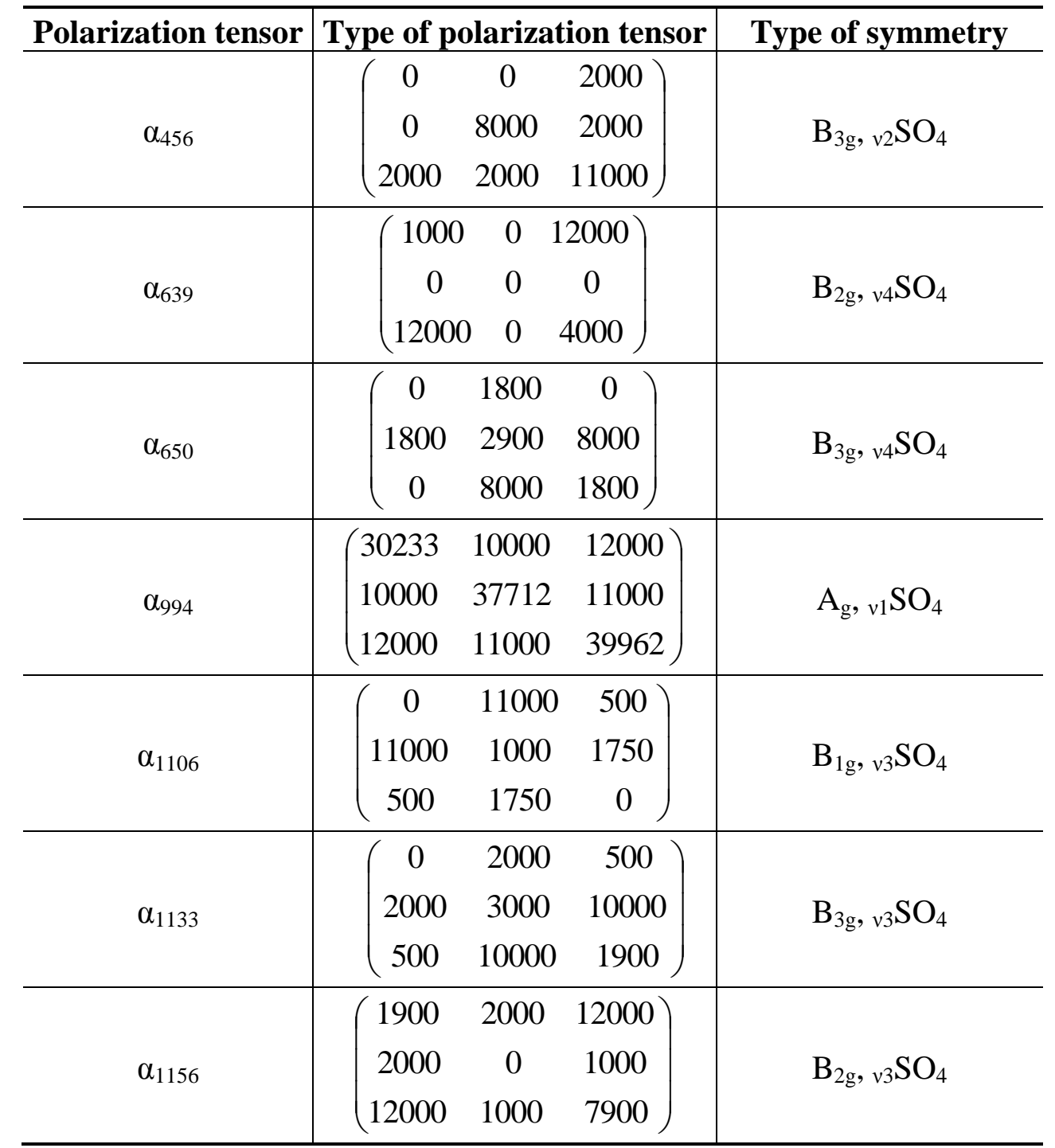

The symmetry of $A_{g}, B_{1 g}, B_{2 g}$ and $B_{3 g}$ vibrations is shown in Equation 7.

$$
A_{g}=\left(\begin{array}{ccc}
a & 0 & 0 \\
0 & b & 0 \\
0 & 0 & c
\end{array}\right) ; B_{1 g}=\left(\begin{array}{ccc}
0 & d & 0 \\
d & 0 & 0 \\
0 & 0 & 0
\end{array}\right) ; B_{2 g}=\left(\begin{array}{ccc}
0 & 0 & e \\
0 & 0 & 0 \\
e & 0 & 0
\end{array}\right) ; B_{3 g}=\left(\begin{array}{ccc}
0 & 0 & 0 \\
0 & 0 & f \\
0 & f & 0
\end{array}\right)
$$

Free isolated $\mathrm{SO}_{4}{ }^{2-}$ ion is a tetrahedron of $T_{d}$ symmetry. Both the theory and experiments mark out four fundamental vibrations $v_{1}\left(A_{1}\right)=983 \mathrm{~cm}^{-1}, v_{2}(E)=450 \mathrm{~cm}^{-1}, v_{3}\left(F_{1}\right)=1,105 \mathrm{~cm}^{-1}$ and $v_{4}\left(F_{2}\right)=611 \mathrm{~cm}^{-1}$, which are observed in Raman and Infra-red spectra (e.g., $A_{1}$ and $E$ only in Raman and $F_{2}$ in both Raman and Infra-red). The interaction between $\mathrm{SO}_{4}{ }^{2-}$ ions and neighboring cations yields the change of $\mathrm{SO}_{4}{ }^{2-}$ vibration symmetry due to the degeneration of vibrations in the lower symmetry. The 
crystal $\mathrm{Na}_{2} \mathrm{SO}_{4}$ has $D_{2 h}$ symmetry, while $\mathrm{SO}_{4}{ }^{2-}$ ion is positioned with the $D_{2}$ local symmetry [35], yielding a vibration symmetry change and the splitting of bands. For example, $v_{2}(E) \rightarrow 2 A_{g}$; $v_{3}\left(F_{1}\right) \rightarrow B_{1 g}+B_{2 g}+B_{3 g}$ and $v_{4}\left(F_{2}\right) \rightarrow B_{1 g}+B_{2 g}+B_{3 g}$ (Table 4), which are observed in Raman and only $2 A_{u}$ with $B_{1 u}+B_{2 u}+B_{3 u}$-in Infra-red spectroscopy. Band splits of $v_{2}(E)$ and $v_{4}\left(F_{2}\right)$ are observed by Raman spectra, which are more informative than those in Infra-red with only a $v_{3}\left(F_{1}\right)$ band.

When the temperature increases from 55 to $300{ }^{\circ} \mathrm{C}$ the vibration bands of $\mathrm{SO}_{4}{ }^{2-}$ are shifted to a lower frequency range, indicating interactions between sulfate groups and $\mathrm{Li}^{+}$cations as well as the presence of aggregated species. In addition, the vibration symmetry of $\mathrm{SO}_{4}{ }^{2-}$ changes with the bands splitting due to interaction with neighboring cations. Later the mobility of $\mathrm{Li}^{+}$cations is modeled in polyelectrolytes at room temperature and experimentally examined in solid electrolytes within a temperature range of 20 to $227^{\circ} \mathrm{C}$.

\subsection{Results of Modeling of Polymeric Electrolytes by the MNDO/d Method}

The modeling of polyelectrolytes is introduced by the examination of the movements of $\mathrm{Li}^{+}$ion along the polymeric chain $\left[\mathrm{CH}_{2}-\mathrm{CH}_{2}-\mathrm{O}\right]_{4}$ through a quantum mechanical calculation in order to determine the conductivity mechanism of polymeric electrolytes $\left(\mathrm{LiCF}_{3} \mathrm{SO}_{3}+(\mathrm{EG})_{\mathrm{n}} \mathrm{DME}, \mathrm{n}=2\right.$ and 11). From the beginning, the positions of $\mathrm{Li}^{+}$ion are considered nearby the first oxygen (model $\mathrm{A}$ in Figure 7). The configuration of the ' $A$ ' system is stable because it is a state at local minimum energy $\left(E_{A}=-3,287.18 \mathrm{kkal} \cdot \mathrm{mol}^{-1}\right)$. If the polyelectrolyte chain is deflected to the right or left, up or down, the configuration becomes unstable and the $\mathrm{Li}^{+}$ion either goes back or approaches its initial position. Later the $\mathrm{Li}^{+}$ion sits between the first and second oxygen atom (i.e., it is shifted to intermediate position in the model $\mathrm{B}$ ). This new configuration is stable due to the local minimum of energy $\left(E_{B}=-3,304.13 \mathrm{kkal} \cdot \mathrm{mol}^{-1}\right)$. Later $\mathrm{Li}^{+}$is positioned close to the second oxygen atom (model C) with acorresponding minimum of energy $\mathrm{E}_{\mathrm{C}}=-3,286.61 \mathrm{kkal} \cdot \mathrm{mol}^{-1}$. Later $\mathrm{Li}^{+}$passes a number of stable configurations with the local minimum of energies $\left(E_{D}=-3,304.63 \mathrm{kkal} \mathrm{mol}^{-1}, \mathrm{E}_{\mathrm{E}}=-3,286.82 \mathrm{kkal} \mathrm{mol}^{-1}\right.$, $\mathrm{E}_{\mathrm{F}}=-3,304.61 \mathrm{kkal} \cdot \mathrm{mol}^{-1}, \mathrm{E}_{\mathrm{G}}=-3,286.60 \mathrm{kkal} \cdot \mathrm{mol}^{-1}, \mathrm{E}_{\mathrm{H}}=-3,319.30 \mathrm{kkal} \cdot \mathrm{mol}^{-1}, \mathrm{E}_{\mathrm{J}}=-3,318.75 \mathrm{kkal} \cdot \mathrm{mol}^{-1}$ and $\mathrm{E}_{\mathrm{K}}=-3,330.75 \mathrm{kkal} \cdot \mathrm{mol}^{-1}$ ) when lithium ion moves along the polymeric chain. The models which are described above are shown in Figure 7.

In addition, there are non-operating transitions ( $\mathrm{L}$ and $\mathrm{M}$ ) which exist between the intermediate states (B, D, F, H and K) (Figure 8). $\mathrm{Li}^{+}$ions move by changing the states with the local minimum of energy due to the states with the local maximum of energy (model $\mathrm{L}$ and $\mathrm{M}$ ) with the close values $\left(E_{\mathrm{L}}=-3,283.80 \mathrm{kkal} \cdot \mathrm{mol}^{-1}\right.$ and $\left.\mathrm{E}_{\mathrm{M}}=-3,287.19 \mathrm{kkal} \cdot \mathrm{mol}^{-1}\right) . \mathrm{Li}^{+}$ions move actively along the polymeric chain due to the rotations of polymer (i.e., carbon permanently rotates around hydrogen, hydrogen rotates around carbon, both carbon and hydrogen rotate around oxygen, etc.). Therefore $\mathrm{Li}^{+}$ ion transports along the polymeric chain by passing through the non-operating positions ( $\mathrm{L}$ and $\mathrm{M}$ ) due to intrapolymeric rotations. $\mathrm{Li}^{+}$ion acquires energies of $\mathrm{E}_{\mathrm{L}}$ and $\mathrm{E}_{\mathrm{M}}$ when carbon atoms get a perpendicular position relatively to each other at the position of $\mathrm{a} \mathrm{Li}^{+}$ion. One requires to transform an additional energy of $\mathrm{E}_{1}=-3.31 \mathrm{kkal} \cdot \mathrm{mol}^{-1}$ in order to move $\mathrm{Li}^{+}$from the position with $\mathrm{E}_{\mathrm{A}}$ to $\mathrm{E}_{\mathrm{B}}$ through $\mathrm{E}_{\mathrm{L}}$ and similarly one donates the $\mathrm{Li}^{+}$by $\mathrm{E}_{2}=-19.28 \mathrm{kkal} \cdot \mathrm{mol}^{-1}$ for transportation from $\mathrm{E}_{\mathrm{B}}$ to $\mathrm{E}_{\mathrm{C}}$ through $\mathrm{E}_{\mathrm{M}}$. The calculations of the minimum energy corresponding to the most probable positions of $\mathrm{a} \mathrm{Li}^{+}$ion nearby the atoms $(\mathrm{C}, \mathrm{H}$ and $\mathrm{O})$ of polymeric chain allow increasing the conductivity of polyethylene oxide with impurities. 
Figure 7. The quantum mechanical modeling (MNDO/d method) of the $\mathrm{Li}^{+}$ion locations along the polymeric chain of polyethylene oxide with the chain fragment $\left[\mathrm{CH}_{2}-\mathrm{CH}_{2}-\mathrm{O}\right]_{\mathrm{n}}$ $(\mathrm{n}=4)$. The capital letters $\mathrm{A}, \mathrm{C}, \mathrm{E}, \mathrm{G}$ and $\mathrm{J}$ are assigned to the states of $\mathrm{Li}^{+}$ion with the local minimum energy (i.e., $\mathrm{E}_{\mathrm{A}}=-3,287.18 \mathrm{kkal} \cdot \mathrm{mol}^{-1}, \mathrm{EC}=-3,286.61 \mathrm{kkal} \cdot \mathrm{mol}^{-1}$, $\left.\mathrm{E}_{\mathrm{E}}=-3,286.82 \mathrm{kkal} \cdot \mathrm{mol}^{-1}, \mathrm{E}_{\mathrm{G}}=-3,286.60 \mathrm{kkal} \cdot \mathrm{mol}^{-1}, \mathrm{E}_{\mathrm{J}}=-3,318.75 \mathrm{kkal} \cdot \mathrm{mol}^{-1}\right)$. The intermediate states of $\mathrm{Li}^{+}$ion along the polymeric chain fragment are ascribed to $\mathrm{B}, \mathrm{D}, \mathrm{F}, \mathrm{H}$ and $\mathrm{K}$ states with the local minimum energy (i.e., $\mathrm{E}_{\mathrm{B}}=-3,304.13 \mathrm{kkal} \cdot \mathrm{mol}^{-1}$, $E_{D}=-3,304.63 \mathrm{kkal} \cdot \mathrm{mol}^{-1}, \mathrm{E}_{\mathrm{F}}=-3,304.61 \mathrm{kkal} \cdot \mathrm{mol}^{-1}, \mathrm{E}_{\mathrm{H}}=-3,319.30 \mathrm{kkal} \cdot \mathrm{mol}^{-1}$, $\left.\mathrm{E}_{\mathrm{K}}=-3,330.75 \mathrm{kkal} \cdot \mathrm{mol}^{-1}\right)$.

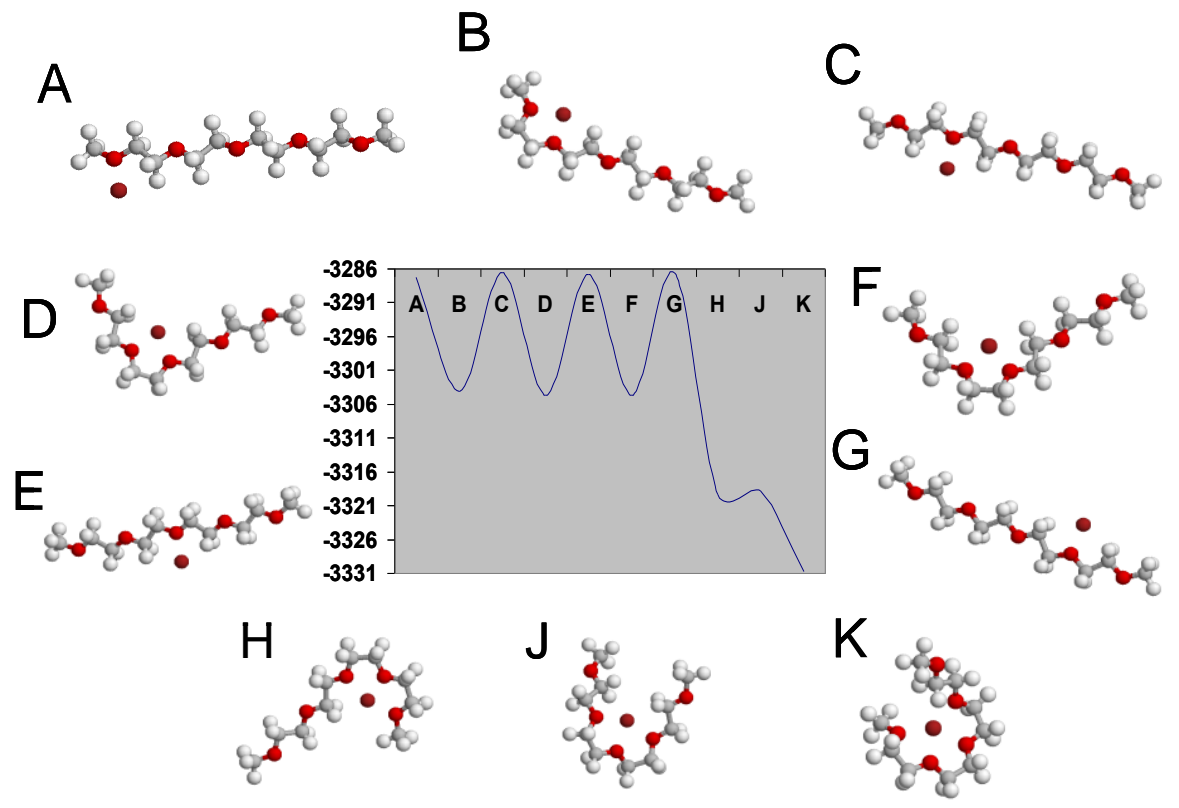

Figure 8. The quantum mechanical calculation of the $\mathrm{Li}^{+}$ion local energies with the non-operating transitions $\mathrm{L}$ and $\mathrm{M}\left(\mathrm{E}_{\mathrm{L}}=-3,283.80 \mathrm{kkal} \cdot \mathrm{mol}^{-1}\right.$ and $\left.\mathrm{E}_{\mathrm{M}}=-3,287.19 \mathrm{kkal} \cdot \mathrm{mol}^{-1}\right)$ which exist between the intermediate states $(\mathrm{B}$, etc. $)$.

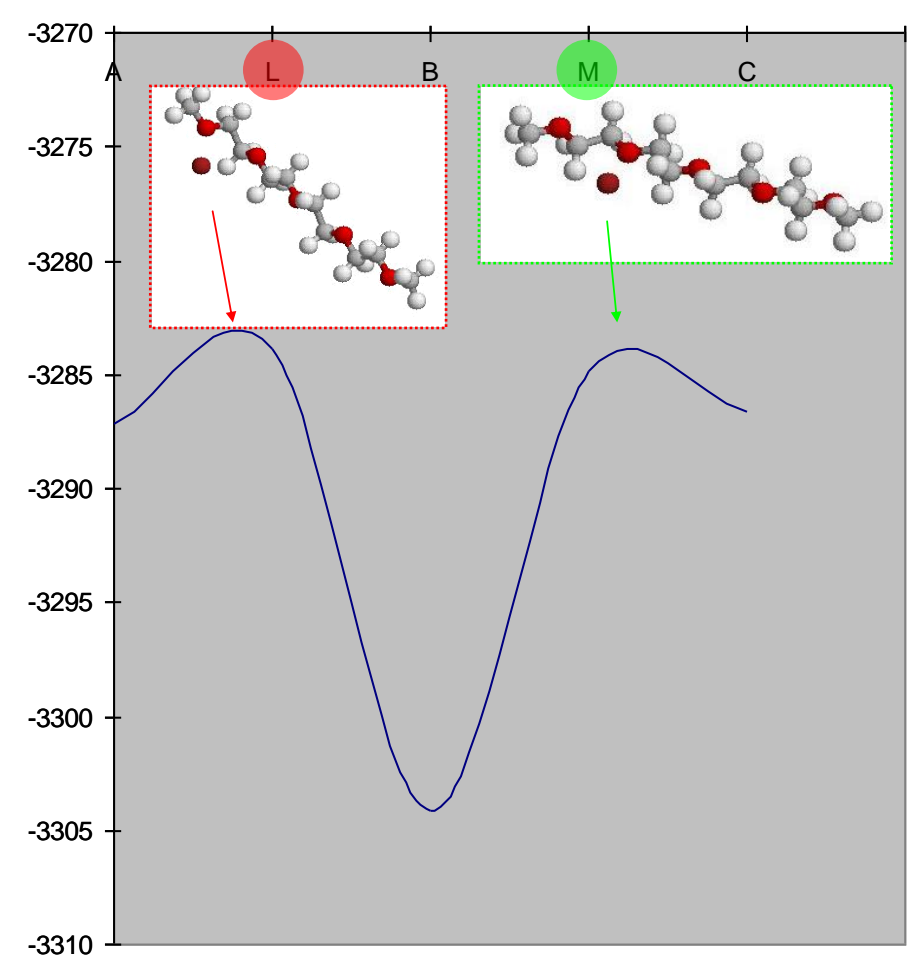




\subsection{The Conductivity Temperature Dependence of Ionic Conductors}

The conductivity of $\mathrm{Li}_{2} \mathrm{SO}_{4}$ versus temperature is measured by a technique reported elsewhere [36]. Conductivity increases with the temperature rise because the $\mathrm{Li}^{+}$ion becomes more mobile due to weaker bonding with other atoms (Table 5). The high mobility of $\mathrm{Li}^{+}$ion can be explained by the mechanism of a 'paddle-wheel', where $\mathrm{Li}^{+}$diffuses into the crystal lattice via an adhesion of sulfate ions in the rotation [37]. This phenomenon results in band shifts to the low frequency region.

Table 5. The dependence of the conductivity of $\mathrm{Li}_{2} \mathrm{SO}_{4}$ on the temperature.

\begin{tabular}{ccc}
\hline $\mathbf{T}\left[{ }^{\circ} \mathbf{C}\right]$ & $\begin{array}{c}\mathbf{1 0}^{\mathbf{3}} \cdot \mathbf{T}^{\mathbf{- 1}} \\
{\left[\mathbf{K}^{\mathbf{- 1}}\right]}\end{array}$ & $\mathbf{L n}(\boldsymbol{\sigma})\left[\mathbf{S} \cdot \mathbf{c m}^{-\mathbf{1}}\right]$ \\
\hline 20 & 3.4 & -4.1 \\
50 & 3.1 & -3.3 \\
78 & 2.9 & -2.8 \\
227 & 2.0 & -1.6 \\
\hline
\end{tabular}

\section{Experimental Section}

\subsection{Materials}

Lithium trifluoromethanesulfonate $\left(\mathrm{LiCF}_{3} \mathrm{SO}_{3}, 99.995 \%\right)$, dimethyl ethylene glycol ([EG $]_{n} \mathrm{DME}$, $\mathrm{n}=2,3$ and 11), lithium sulfate dihydrate $\left(\mathrm{Li}_{2} \mathrm{SO}_{4} \cdot 2 \mathrm{H}_{2} \mathrm{O}, \geq 99.99 \%\right)$, sodium sulfate dihydrate $\left(\mathrm{Na}_{2} \mathrm{SO}_{4} \cdot 2 \mathrm{H}_{2} \mathrm{O}, \geq 99.99 \%\right)$ were purchased from Sigma-Aldrich (Munich, Germany).

\subsection{Preparation of $\mathrm{Li}_{2} \mathrm{SO}_{4}$ and $\mathrm{Na}_{2} \mathrm{SO}_{4}$ Crystals and Polymeric Electrolytes}

$\mathrm{Li}_{2} \mathrm{SO}_{4}$ and $\mathrm{Na}_{2} \mathrm{SO}_{4}$.crystals were grown by slow evaporation at different temperatures. The aqueous solutions were heated until $80{ }^{\circ} \mathrm{C}$, filtered, slowly cooled with a step 5-10 ${ }^{\circ} \mathrm{C}$ until $30^{\circ} \mathrm{C}$ and dried; but not completely in order to avoid possible contamination by the rest of the impurities contained in the bulk of the material. These formed crystals are colorless with a morphology at the mm scale.

Polymeric electrolytes, which are produced on the basis of dimethyl ethylene glycol $\left((\mathrm{EG})_{\mathrm{n}} \mathrm{DME}\right)$ were dried in vacuum in order to remove water traces. $\mathrm{LiCF}_{3} \mathrm{SO}_{3}$ was dried at $120{ }^{\circ} \mathrm{C}$ under vacuum $\left(10^{-3}\right.$ bar) during 24 hours. The mixture of $\mathrm{LiCF}_{3} \mathrm{SO}_{3}$ in ethylene glycol was prepared at $50{ }^{\circ} \mathrm{C}$ in a micro chamber under argon atmosphere. $\mathrm{LiCF}_{3} \mathrm{SO}_{3}$ was dissolved in oligomers (EG) ${ }_{n} \mathrm{DME}$ with $\mathrm{n}=2$ and 3. The molar ratio of $\mathrm{Li} / \mathrm{EO}\left(\mathrm{LiCF}_{3} \mathrm{SO}_{3}\right.$ to ethylene oxide) was varied from 0 to 0.4 .

\subsection{FTIR Measurements}

a) At Room Temperature

$\mathrm{Li}_{2} \mathrm{SO}_{4}$ crystals $\left(4 \times 10^{-3} \mathrm{~g}\right)$ and $\mathrm{KBr}\left(846 \times 10^{-3} \mathrm{~g}\right)$ were ground into a powder and pressed to form a pellet $\left(0.47 \%\right.$ of $\mathrm{Li}_{2} \mathrm{SO}_{4}$ crystals $)$ by putting the mixture into a press-shape $\left(150 \mathrm{~kg} \cdot \mathrm{cm}^{-2}\right)$ with a 
diameter of $12 \mathrm{~mm}$ under high pressure (150 atm). The pellets and $\mathrm{Li}_{2} \mathrm{SO}_{4}$ crystals were kept in a waterproof reservoir in order to avoid contact with air. The Fourier transformed infrared spectra (FTIR) of prepared $\mathrm{Li} / \mathrm{KBr}$ pellets were measured employing the Bruker IFS66 Fourier spectrometer with Raman module FRA106 in the middle infra-red region $(2.5-25 \mu \mathrm{m})$ with a spectral resolution $2 \mathrm{~cm}^{-1}$ at a laser $(1,064 \mathrm{~nm})$ power of $3 \times 10^{-5} \mathrm{~V} .400$ scans. A 10 min scan was added for each spectrum, in order to get a good signal/noise ratio. Raman intensities were determined as integral intensities. The $v(\mathrm{CO})$ and $v(\mathrm{CC})$ bands of pure polymer at $1,032 \mathrm{~cm}^{-1}$ were subtracted from the reaction spectra. Raman bands were factorized into Gaussian-Lorentz function and a linear baseline in the spectral range $740 \mathrm{~cm}^{-1}$.

b) In the Temperature Range from $22{ }^{\circ} \mathrm{C}$ to $250^{\circ} \mathrm{C}$

The temperature dependence of Raman spectra was measured employing a temperature add-on device R495 from Bruker (Figure SI.2, supporting information) and a special home made thermostat set-up for this purpose (thermo-isolator box with a metallic net inside, Figure SI.3, supporting information). The voltage power supply in the in-built electro-heater $(85 \mathrm{~W})$ was completely on or off in a range of 0 to $12 \mathrm{~V}$, while the temperature was increased from $22{ }^{\circ} \mathrm{C}$ to $250{ }^{\circ} \mathrm{C}$ with a stability $\pm 3{ }^{\circ} \mathrm{C}$. The calibration curves of the thermocouple (thermo electromobile force, EMF, versus temperature) in the temperature add-on device and special home made thermostat are shown in Figure SI.4 (supporting information).

\subsection{Theoretical Calculations (Method MNDO)}

The MNDO method is based on stationary Schrödinger equations. MNDO (Modified Neglect of Differential Overlap) is a modified method of NDDO (Neglect of Diatomic Differential Overlap) and semi-empirical method, which is oriented to the correct reproduction of electron characteristics such as dipole moments, non-transformation heat and geometry of molecules. The atomic orbital is of spherical symmetry in the calculations of electron-electron repulsion integrals. The orientation of p-orbitals is considered in the calculation of n-centered $(n=1-4)$ integrals of atomic orbital repulsion of the same atom. The self-descriptiveness of MNDO is due to information not only from the geometry of the molecule, but also dipole moments, the heat of the formation, the order of bonds, and spinning and density ratios among other factors.

MNDO is employed for a more accurate description of the repulsion between unshared electronic couples [38]. One of the main advantages of MNDO is the calculation of unsaturated compounds and molecules, which contain unshared electronic couples within neighboring atoms (for polar molecules). In addition, valent angles and the consistency of molecular orbital levels are accurately calculated through this method. MNDO correctly reproduces a relative stability of isomers, which contain double and triple bonds, and is widely used for a calculation of the oscillation frequency and structure of linear polymers. Moreover, MNDO is applied to polyyne and paracyclophan molecules, yielding high results for fluorine compounds (e.g., F-O, F-N, etc.) as well as a good reproduction of oscillation frequency. The disadvantages of MNDO are as follows: i) an incorrect description of hydrogen bonds; ii) an inaccurate calculation of internal rotation barriers in the conjugate molecules (e.g., benzylideneaniline, stilbene and azobenzene); iii) a disability to calculate four-termed cycles (they are 
too planar and stable); and, iv) a systematic overstating of ionization potentials in compounds, which contain $\mathrm{Cl}^{-}$and $\mathrm{Br}^{-}$anions Despite these disadvantages, MNDO/d (modified version of MNDO) is applied to model the interactions between $\mathrm{Li}^{+}$and polyethylene oxide.

\section{An Algorithm of Calculations by MNDO}

Normally nuclei are considered to be static, while electrons are mobile. Given these considerations, it is possible to solve the Schrödinger equation for the one-electron system only. For this reason the most applied method is the method of self-consistent fields (SCF) or Hartree-Fock in quantum-chemical theory. In this method any electron moves in the field of atomic nuclei and in the effective averaged field of other electrons. Multielectron wave function is considered as an asymmetric product of spin-orbitals (i.e., one-electron molecular orbitals $(\mathrm{MO}), \varphi_{i}(m)$, which are multiplied by spin wave functions $\alpha$ and $\beta$ of the corresponding electron [38]:

$$
\phi=\left\|\phi_{1} a \cdot \phi_{1} b \cdot \phi_{2} a \cdot \phi_{2} b \cdots \phi_{N} a \cdot \phi_{N} b\right\|
$$

Restricted, the Hartree-Fock method (RHF) is used for systems with closed shells (without unpaired electrons), where each electron MO $\varphi_{i}(m)$ is occupied by two electrons with opposite spins. The Schrödinger equation is transformed into a system of integral-differential equations to describe the movement of each separate electron:

$$
F \cdot \phi_{i}=e_{i} \cdot \phi_{i}^{\prime}
$$

where $\mathrm{F}$ is a Fokian (i.e., special kind of a Hamiltonian in the SCF approximation) and $\mathrm{e}_{\mathrm{i}}$ is the energy of $\mathrm{MO}_{\mathrm{i}}$.

Molecular orbitals $\varphi_{i}(m)$ for linear combinations of atomic orbitals $x_{j}(m)$ (LCAO approximation) is as follows

$$
\phi_{i}(m)=\sum_{j}\left\lfloor C_{m j}(m) \cdot x_{j}(m)\right\rfloor
$$

where $C_{m j}$ is the desired coefficient.

The group of atomic orbitals (AO), $x_{j}$, is the basis for a molecular construction wave function $\varphi_{i}$. This basis is incomplete due to the relatively small number of basic AO. The distribution of electron density in the molecule can be transmitted by the AO basis with the challenge in its choice [38].

This system of linear equations below is used to find the minimum of full molecule electron energy $E$ as well as $C_{m j}$.

$$
\begin{gathered}
\sum_{j}\left\lfloor\left(\left(F_{i j}-e_{m} S_{i j}\right) \cdot C_{m j}\right)=0\right\rfloor \\
F_{i j}=F_{i j}{ }^{\prime}+\sum_{k, l}\left[P_{k l}(\langle i j\rangle)\right] \\
F_{i j}=\sum_{k l}\left[P_{k l}\left(\langle i j \mid k l\rangle-\frac{1}{2}\langle i k \mid j l\rangle\right]\right.
\end{gathered}
$$

where $S_{m j}$ is the overlapping integral of $\mathrm{AO} x_{i}$ and $x_{j}, F_{i j}{ }^{\prime}$ is the matrix element of one-electron Hamiltonian, which includes kinetic energy of electrons and energy of interaction of electrons and atomic 
nuclei, $P_{k l}$ is the matrix of charges and bond orders, $\langle i j \mid k l\rangle$ is the Coulomb two-electron integral

$$
\langle i j \mid k l\rangle=\int\left[x_{i}^{*}(1) x_{j}^{*}(1) \cdot 1 / r_{12} \cdot x_{k}(2) x_{l}(2) d t_{1} d t_{2}\right]
$$

This system of Equation 14 is solved by a self-agreement method with $C_{m j}$ as the random group and the matrix $F_{i j}$, which is derived from the group of coefficients. The solution (11) gives new $C_{m j}$ and $F_{i j}$ until $C_{m j}$ is the same. This calculation is carried out for the valence electrons with the minimal basis and a considerable part of Coulomb integrals is neglected (13). In this work, the method MNDO/d is used to calculate local minimal energies during the interaction of Li atoms with the polymeric chain of polyethylene oxide.

\section{Conclusions}

Polyethylene oxide acquires the properties of a conductor and becomes a polymeric electrolyte when it is doped by $\mathrm{LiCF}_{3} \mathrm{SO}_{3}$. This conductivity can be controlled by monitoring the vibrations of $\mathrm{SO}_{3}{ }^{-}$groups at $\mathrm{EO} / \mathrm{Li}$ molar ratio from 10 to 30 in $\mathrm{LiCF}_{3} \mathrm{SO}_{3}+(\mathrm{EG})_{\mathrm{n}} \mathrm{DME}(\mathrm{n}=2,3,11)$. At the high $\mathrm{EO} / \mathrm{Li}$ ratio the intensity of bands increases and a triplet appears at $1,045 \mathrm{~cm}^{-1}$, indicating the presence of free anions, ionic pairs and aggregates. The existence of free ions in the polymeric electrolyte is also proven by red shift of bands in Raman spectra within a temperature range of 16 to $90{ }^{\circ} \mathrm{C}$. In addition, a shift of bands in the monocrystal $\mathrm{Li}_{2} \mathrm{SO}_{4} \cdot 2 \mathrm{H}_{2} \mathrm{O}$ to the low frequency region is observed in the Infra-red at $65<\mathrm{T}<355{ }^{\circ} \mathrm{C}$, as measured by the home made temperature device located inside the spectrometer. In the Raman spectra of $\mathrm{Na}_{2} \mathrm{SO}_{4}$ the symmetry of $\mathrm{SO}_{4}{ }^{2-}$ vibrations is changed due to an interaction with neighboring cations resulting in the disposal of a degeneration of vibrations, leading to a band split.

From the quantum mechanical modelling (method MNDO/d), the energies (minimum and maximum) corresponding to the most probable and stable positions of $\mathrm{Li}^{+}$are calculated in order to gain deeper insight into the conductivity of polymeric electrolytes. While being transported along the polymeric chain, $\mathrm{Li}^{+}$ion overcomes intermediate states (minimum energy) through non-operating transitions (maximum energy) due to permanent intrapolymeric rotations (rotation of $\mathrm{C}, \mathrm{H}$ and $\mathrm{O}$ atoms around each other). The conductivity of the monocrystal $\mathrm{Li}_{2} \mathrm{SO}_{4} \cdot 2 \mathrm{H}_{2} \mathrm{O}$ increases with a temperature rise of 20 to $227{ }^{\circ} \mathrm{C} \mathrm{Li}^{+}$ions become more free and mobile resulting in an increase of the conductivity of a pellet-sample $\mathrm{Li}_{2} \mathrm{SO}_{4} \cdot 2 \mathrm{H}_{2} \mathrm{O}$.

The results of this present work can be of practical interest for the direct production of small and effective devices in science and industry that use polymeric electrolytes, which are formed by combining polyethylene oxide and $\mathrm{LiCF}_{3} \mathrm{SO}_{3}$ as well as solid electrolytes (e.g., $\mathrm{Li}_{2} \mathrm{SO}_{4}$ ).

\section{Acknowledgements}

This work is supported by the FP6EU Project. The author thanks S. N. Shashkov from Department of Physics in Belarusian State University (BSU, Minsk, Belarus) for useful discussions and supporting materials. A. Kulak (BSU, Department of Physics, Minsk, Belarus) is acknowledged for careful reading the manuscript. 


\section{References}

1. Manea, C.; Mulder, M. New polymeric electrolyte membranes based on proton donor-proton acceptor properties for direct methanol fuel cells. Desalination 2002, 147, 179-182.

2. Corbo, P.; Migliardini, F.; Veneri, O. Dynamic behaviour of hydrogen fuel cells for automotive application. Renewable Energy 2009, 34, 1955-1961.

3. Morita, M.; Qiao, J.L.; Yoshimoto, N.; Ishikawa, M. Application of proton conducting polymeric electrolytes to electrochemical capacitors. Electrochim. Acta 2004, 50, 837-841.

4. Bukun, N.G.; Moskvina, E.I.; Ukshe, E.A. Impedance of a Silver electrode and the conductivity of a solid electrolyte of the nasicon type. Sov. Electrochem. 1986, 22, 1240-1244.

5. Delhommelle, J.; Cummings, P.T.; Petravic, J. Conductivity of molten sodium chloride in an arbitrarily weak dc electric field. J. Chem. Phys. 2005, 123, 114501-114505.

6. Zimmerman, G.H.; Scott, P.W.; Greynolds, W. A new flow instrument for conductance measurements at elevated temperatures and pressures: Measurements on $\mathrm{NaCl}(\mathrm{aq})$ to $458 \mathrm{~K}$ and 1.4 MPa. J. Solut. Chem. 2007, 36, 767-786.

7. Butman, M.F.; Smirnov, A.A.; Kudin, L.S. Munir, Z.A. Mass-spectrometric study of the kinetics of ionic and molecular sublimation of sodium chloride single crystals. J. Mater. Synth. Process. 1999, 7, 379-385.

8. Ramires, M.L.V.; Decastro, C.A.N.; Fareleira, J. Wakeham, W.A. Thermal-Conductivity of Aqueous Sodium-Chloride Solutions. J. Chem. Eng. Data 1994, 39, 186-190.

9. Corish, J.; Jacobs, P.W.M. Ionic Conductivity of Silver-Chloride Single-Crystals. J. Phys. Chem. Solid. 1972, 33, 1799-1818.

10. Tiwari, J.P.; Rao, C.R.K. Template synthesized high conducting silver chloride nanoplates. Solid State Ionics 2008, 179, 299-304.

11. Panero, S.; Scrosati, B.; Sumathipala, H.H.; Wieczorek, W. Dual-composite polymer electrolytes with enhanced transport properties. J. Power Sour. 2007, 167, 510-514.

12. Ciosek, M.; Sannier; L.; Siekierski, M.; Golodnitsky, D.; Peled, E.; Scrosati, B.; Glowinkowski, S.; Wieczorek, W. Ion transport phenomena in polymeric electrolytes. Electrochim. Acta 2007, 53, 1409-1416.

13. Morita, M.; Shirai, T.; Egashira, M.; Yoshimoto, N. Conductance behavior of polymeric ion-gel containing magnesium salt. Electrochemistry 2005, 73, 579-581.

14. Florjanczyk, Z.; Zygadlo-Monikowska, E.; Rogalska-Jonska, E.; Krok, F.; Dygas, J.R.; Misztal-Faraj, B. Polymer electrolytes based on PEO and aluminum carboxylates. Solid State Ionics 2002, 152, 227-234.

15. Rahman, M.Y.A.; Ahmad, A.; Mangsor, M.R. Wahab, S.A. Temperature dependence on conductivity and thermal properties of a solid polymeric electrolyte of PVC-ZnO-LiClO ${ }_{4}$ Phys. B-Condens. Matter 2008, 403, 3414-3416.

16. Licoccia, S.; Traversa, E. Increasing the operation temperature of polymer electrolyte membranes for fuel cells: From nanocomposites to hybrids. J. Power Sour. 2006, 159, 12-20.

17. Armand, M.B.; Chabagno, J.M.; Duclot, M. Fast Ion Transport in Solids; North-Holland: New York, NY, USA, 1979; pp. 131-136. 
18. Ziegler, G.E. The crystal structure of lithium sulphate mono-hydrate, $\mathrm{Li}_{2} \mathrm{SO}_{4} \mathrm{H}_{2} \mathrm{O}$. Z. Krist. 1934, 89, 456-461.

19. Larson, A.C.; Helmholz, L. Redetermination of the Crystal structure of lithium sulfate monohydrate $\mathrm{Li}_{2} \mathrm{SO}_{4} \mathrm{H}_{2}$ o. J. Chem. Phys. 1954, 22, 2049-2050.

20. McGrath, J.W.; Silvidi, A.A.; Carroll, J.C. Proton magnetic resonance study of lithium sulfate monohydrate. J. Chem. Phys. 1959, 31, 1444-1449.

21. Bansal, M.L.; Roy, A.P. Orientational phase-transition in $\mathrm{LiKSO}_{4}$. Phys. Rev. B 1984, 30, 7307-7309.

22. Moreira, R.L.; Bourson, P.; Leitao, U.A.; Righi, A.; Belo, L.C.M.; Pimenta, M.A. Raman and birefringence studies of the low-temperature phase-transitions in $\mathrm{LiK}_{1-\mathrm{x}} \mathrm{Rb}_{\mathrm{x}} \mathrm{SO}_{4}$ crystals. Phys. Rev. B 1995, 52, 12591-12600.

23. Cazzanelli, E.; Frech, R. Raman-spectra of ${ }^{7} \mathrm{Li}_{2} \mathrm{SO}_{4}$ and ${ }^{6} \mathrm{Li}_{2} \mathrm{SO}_{4}$. J. Chem. Phys. 1983, 79, 2615-2620.

24. Petersen, G.; Torell, L.M.; Panero, S.; Scrosati, B.; Dasilva, C.J.; Smith, M. Ionic interactions in $\mathrm{MCF}_{3} \mathrm{SO}_{3}$-polyether complexes containing monovalent, divalent and trivalent cations. Solid State Ionics 1993, 60, 55-60.

25. Xu, W.Y.; Smid, J.; Vanbeylen, M. Structure of ion-pairs in solid polymer electrolytes. Solid State Ionics 1992, 57, 133-139.

26. Schantz, S.; Torell, L.M.; Stevens, J.R. Raman and brillouin-scattering of $\mathrm{LiClO}_{4}$ complexed in poly(propylene-glycol). J. Appl. Phys. 1988, 64, 2038-2043.

27. Papke, B.L.; Ratner, M.A.; Shriver, D.F. Vibrational spectroscopic determination of structure and ion-pairing in complexes of poly(ethylene oxide) with lithium-salts. J. Electrochem. Soc. 1982, 129, 1434-1438.

28. Huang, W.W.; Frech, R. Dependence of ionic association on polymer-chain length in poly(ethylene oxide)-lithium triflate complexes. Polymer 1994, 35, 235-242.

29. Watanabe, M.; Endo, T.; Nishimoto, A.; Miura, K.; Yanagida, M. High ionic conductivity and electrode interface properties of polymer electrolytes based on high molecular weight branched polyether. J. Power Sour. 1999, 81, 786-789.

30. Allcock, H.R.; Napierala, M.E.; Olmeijer, D.L.; Cameron, C.G.; Kuharcik, S.E.; Reed, C.S.; O’Connor, S.J.M. New macromolecules for solid polymeric electrolytes. Electrochim. Acta 1998, 43, 1145-1150.

31. Papke, B.L.; Ratner, M.A.; Shriver, D.F. Conformation and ion-transport models for the structure and ionic-conductivity in complexes of polyethers with alkali-metal salts. J. Electrochem. Soc. 1982, 129, 1694-1701.

32. Smith, H.G.; Peterson, S.W.; Levy, H.A. Neutron-diffraction study of lithium sulfate monohydrate. J. Chem. Phys. 1968, 48, 5561-5565.

33. Larson, A.C. Crystal structure of $\mathrm{Li}_{2} \mathrm{SO}_{4} 2 \mathrm{H}_{2} \mathrm{O}$ a 3-dimensional refinement. Acta Crystallogr. 1965, 18, 717-724.

34. Neises, B.; Steglich, W. 4-Dialkylaminopyridines as Acylation Catalysts. 5. Simple Method for Esterification of Carboxylic-Acids. Angew. Chem.-Int. Ed. Engl. 1978, 17, 522-524.

35. Poulet, H.; Mathieu, J.P. Vibration Spectra and Symmetry of Crystals; Gordon and Breach: New York, NY, USA, 1976; p. 571. 
36. Singh, K., Bhoga, S.S. The ion conduction mechanism of isovalent cation-doped $\mathrm{Li}_{2} \mathrm{SO}_{4}$. Appl. Phys. A 1998, 67, 475-481.

37. Suleimany, B.M., Gustavssonz, M., Karawacki, E., Lunden, A. Thermal properties of lithium sulphate. J. Phys. D Appl. Phys. 1997, 30, 2553-2560.

38. Clark, T. A Handbook of Computational Chemistry; John Wiley and Sons: Hoboken, NJ, USA, 1985; pp. 12-95.

(C) 2011 by the authors; licensee MDPI, Basel, Switzerland. This article is an open access article distributed under the terms and conditions of the Creative Commons Attribution license (http://creativecommons.org/licenses/by/3.0/). 